\title{
Article
}

\section{The influence of picosecond laser generated periodic structures on bacterial behaviour}

Rajab, Fatema H., Tariq A.S., Tayf, Al-Jumaily, Anmar K., Alshaer, Ahmad W., Li, Lin and Whitehead, Kathryn A.

Available at http://clok.uclan.ac.uk/39223/

Rajab, Fatema H., Tariq A.S., Tayf, Al-Jumaily, Anmar K., Alshaer, Ahmad W. ORCID: 0000-0002-5031-8493, Li, Lin and Whitehead, Kathryn A. (2021) The influence of picosecond laser generated periodic structures on bacterial behaviour. Applied Surface Science, 540 (Part 1). p. 148292. ISSN 0169-4332

It is advisable to refer to the publisher's version if you intend to cite from the work. http://dx.doi.org/10.1016/j.apsusc.2020.148292

For more information about UCLan's research in this area go to http://www.uclan.ac.uk/researchgroups/ and search for <name of research Group>.

For information about Research generally at UCLan please go to http://www.uclan.ac.uk/research/

All outputs in CLoK are protected by Intellectual Property Rights law, including Copyright law. Copyright, IPR and Moral Rights for the works on this site are retained by the individual authors and/or other copyright owners. Terms and conditions for use of this material are defined in the policies page.

\section{CLoK}

Central Lancashire online Knowledge www.clok.uclan.ac.uk

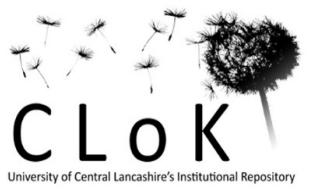


The influence of picosecond laser generated periodic structures on bacterial behaviour

Fatema H. Rajab ${ }^{1, *}$, Tayf Tariq A.S. ${ }^{2}$, Anmar K. Al-Jumaily ${ }^{1}$, Ahmad W. AlShaer ${ }^{3}$, Lin Li $^{4}$ and Kathryn A. Whitehead

${ }^{1}$ Laser and Optoelectronics Engineering Department, College of Engineering, Al-Nahrain University, Baghdad, Iraq

${ }^{2}$ University of Information Technology and Communication, Baghdad, Iraq

${ }^{3}$ School of Engineering, University of Central Lancashire (UCLan), Preston, UK

${ }^{4}$ Laser Processing Research Centre, School of Engineering, Department of Mechanical, Aerospace, and Civil Engineering, The University of Manchester, Manchester, M13 9PL, UK

${ }^{5}$ Microbiology at Interfaces, Manchester Metropolitan University, Manchester, M1 5GD, UK

Corresponding author*Fatema H. Rajab, fatema.rajab@eng.nahrainuniv.edu.iq, fatema.h.rajab@ced.nahrainuniv.edu.iq, fatema.hamid.rajab@gmail.com. 


\section{Abstract}

The formation of a biofilm is preceded by bacterial retention and proliferation on a surface. Biofilm development on surfaces can cause numerous issues in terms of fouling and bacterial transmission and contamination. The design and fabrication of surfaces that prevent bacterial retention and biofilm formation may provide a potential solution to reduce bacterial fouling of surfaces. An EdgeWave, Nd:YVO 4 picosecond laser was used to generate two periodic surface topographies on $316 \mathrm{~L}$ stainless steel surfaces with and without fluoroalkylsilane (FAS) treatment. These were characterised using Optical Laser Microscopy (OLM), Scanning Electron Microscopy (SEM), contact angle measurements, and Energy Dispersive X-ray Spectroscopy (EDX). The surface wettability and retention of Escherichia coli bacteria on the laser generated surfaces were analysed over one month. Without chemical treatment, and with increasing the time to one month, the results showed that the wettability of laser treated surfaces was decreased as was subsequent bacterial retention. However, the control surface recorded the lowest number of adhered bacteria. After reducing the surface tension, the number of bacteria retention was decreased on all surfaces and one of laser generated surfaces which presented higher contact angle and lower surface tension components $\left(\mathrm{CA}=132^{\circ}, \Delta \mathbf{G}_{\mathbf{i w i}}=\right.$ 85.26, $\gamma_{\mathbf{s}}=13.81, \gamma_{\mathbf{s}} \mathbf{L W}=13.37$, and $\left.\gamma_{\mathbf{s}}{ }^{-}=0.13\right)$. The results showed that reducing the surface tension played an important role which reduced bacterial fouling.

Keywords: Picosecond laser; Laser Induced Periodic Surface Structuring (LIPSS); surface tension; wettability; bacteria retention; biofilm 


\section{Introduction}

Laser-induced periodic structures surface structures (LIPSS), which were first observed by Birnbaum in 1965 following the Ruby laser processing of a semiconductor, and these are among the most widely studied processed surfaces used for various medical and engineering applications [1]. It has been observed that the periodicity of the structures is dependent on the laser processing parameters and such features can usually be generated with periods in the order of the laser wavelength and can be arranged perpendicularly to the polarisation of the incident laser beam [2-5]. Ripples were observed on the surface by machining the surface using low laser fluence which is normally higher than the material's ablation threshold while low number of pulses causes the formation of ripples [6]. Moreover, the ripple periodicity including the trenches width and depth have also been studied and have been found to be increased by increasing the laser fluence [7-9]. At specific fluence, the width and depth of the periodic structure could be decreased by increasing the number of pulses, decreasing the scanning speed and/or increasing the number of passes [9-11]. Researchers also found that increasing the number of pulses or decreasing the scanning speed transformed the LIPSS shape to different microstructures such as formation of grooves and micropores [12-15]. It was also found that the trenches of LIPSS generated on various substrates using a femtosecond laser beam were smaller and deeper when produced in water rather than in air, indicating that the processing environment significantly affected the periodicity of the LIPSS features $[3,15,16]$. Laser polarisation can also affect the LIPSS formation and researcher recommended the use of smaller number of pulses in case of linear polarisation than that used for circularly polarised laser beams [17].

In nature, there are many plants such as lotus leaf whose surfaces are kept clean due to the microstructures created on such surfaces which result in a self-cleaning action. These surfaces are superhydrophobic with a contact angle equal to or larger than $150^{\circ}$ with a sliding angle less 
than $5^{\circ}$. Such parameters enable water droplets to roll off, removing particulate matter [18]. These surfaces have been suggested to have properties efficient for use in several applications including those that require the reduction of bacteria fouling [19].

Although it has been previously shown that generating superhydrophobic structures on stainless steel surfaces with low surface energy characteristics can reduce bacteria retention, the wettability of the metallic surface changes with time [19-22]. Such decreases in the surfaces wettability can be significant altered directly after laser treatment, due to the adsorption of organic and carbon contents onto the surface from the atmosphere [23]. In order to control such changes in the surface wettability and energy, surface may be chemically treated following laser ablation $[15,20-22,24]$. In this work, the effect of laser generated structures with and without chemical modification and their effect on bacterial retention over time was characterised.

\section{Experimental procedure}

\subsection{Surface preparation}

AISI 316L stainless steel samples used in this work, obtained from RS components, UK, were cut into $10 \mathrm{~mm} \times 10 \mathrm{~mm} \times 0.7 \mathrm{~mm}$ sheets. The thermophysical properties and chemical composition were determined from Energy Dispersive X-ray Spectroscopy (EDX) analysis (Table 1 and 2 respectively). Before laser processing, the samples were ultrasonically cleaned with $99 \%$ ethanol and rinsed in De-Ionised Water (DIW) for 10 minutes. 
Table 1. The thermophysical properties of 316L stainless steel [25-27]

\begin{tabular}{lc}
\hline Density $\left(\mathrm{Kg} / \mathrm{m}^{3}\right)$ & 7950 \\
\hline Specific heat capacity $(\mathrm{J} / \mathrm{kgK})$ & 470 \\
\hline Thermal conductivity $(\mathrm{W} / \mathrm{mK})$ & 20 \\
\hline Reflectivity at $\lambda=1064 \mathrm{~nm}$ & $50 \%$ \\
Reflectivity at $\lambda=532 \mathrm{~nm}$ & $40 \%$ \\
\hline Melting point, $\mathrm{T}_{\mathrm{m}}(\mathrm{K})$ & 1400 \\
\hline Boiling point, $\mathrm{T}_{\mathrm{b}}(\mathrm{K})$ & 3100 \\
\hline Latent heat of fusion, $L_{v}(\mathrm{~kJ} / \mathrm{kg})$ & 272 \\
\hline Latent heat of vaporisation, $L_{b}(\mathrm{~kJ} / \mathrm{kg})$ & 6364 \\
\hline
\end{tabular}

Table 2. Chemical composition of the 316L (Numbers between brackets indicate the standard deviation)

\begin{tabular}{|c|c|c|c|c|}
\hline Element & $\mathbf{F e}$ & $\mathbf{C r}$ & $\mathbf{N i}$ & Mo \\
\hline $\mathbf{\%}$ & $69.59(0.08)$ & $18.75(0.03)$ & $10.03(0.02)$ & $1.62(0.07)$ \\
\hline
\end{tabular}

An EdgeWave Nd:YVO 4 picosecond laser (repetition rate $=103 \mathrm{kHz}$ ) was used to ablate the stainless steel sheets using the following specifications (Table 3).

Table 3. The properties of picosecond laser [28]

\begin{tabular}{lc}
\hline Max. average power $(\mathrm{W})$ & 400 \\
\hline Max. repetition rate $(\mathrm{MHz})$ & 20 \\
\hline Focused beam spot size $(\mu \mathrm{m})$ & 125 \\
\hline Wavelength $(\mathrm{nm})$ & $1064(\mathrm{IR})$ \\
\hline Highest beam quality $\left(\mathrm{M}^{2}\right)$ & 1.1 \\
\hline Pulse width $(\mathrm{ps})$ & 1 \\
\hline Energy stability $(\%) \mathrm{rms}$ & $>100.1$ \\
\hline Polarisation & $<10$ \\
\hline Beam ellipticity (far field) $(\%)$ & 3 \\
\hline Diameter at window $(\mathrm{mm})$ & 500 \\
\hline Full divergence angle $(\mu \mathrm{rad})$ & $<100$ \\
\hline Point stability $(\mu \mathrm{rad})$ & \\
\hline
\end{tabular}


Laser texturing was performed in air using a raster scanning pattern (parallel lines) to prepare two different periodic structures using the parameters (Table 4). The incorporated Galvo scanning system (type: Scanlab Curryscan 20) had scan rates up to $10 \mathrm{~m} / \mathrm{s}$. The Galvo system was located on a PRO 165 Aerotech vertical Z-axis: $2 \mu \mathrm{m}$ accuracy, $400 \mathrm{~mm}$ traverse range, $150 \mathrm{~mm} / \mathrm{s}$ maximum velocity and $0.5 \mu \mathrm{m}$ resolution. The specimen stage was an Aerotech high dynamic XY-linear motor table: maximum load $75 \mathrm{~kg}$, maximum velocity $500 \mathrm{~mm} / \mathrm{s}$, $20 \mathrm{~nm}$ resolution, maximum acceleration $0.5 \mathrm{~g}$, and $400 \mathrm{~mm} \times 400 \mathrm{~mm}$ traverse. The Galvo system and sample stage were controlled using computer and display system (G\&M codes) with Windows-based software to control the laser, the scanner and the translation tables, for generating patterns on the samples [29].

Table 4. Laser parameters for producing two structures on stainless steel substrate

\begin{tabular}{cccc}
\hline Surface & Fluence $\left[\mathbf{J} / \mathbf{c m}^{2}\right]$ & Laser speed $[\mathbf{m m} / \mathbf{s}]$ & Hatch distance $[\boldsymbol{\mu m}]$ \\
\hline S1 & 0.178 & 100 & 80 \\
\hline S2 & 0.1345 & 1000 & 50 \\
\hline
\end{tabular}

\subsection{Surface production}

The samples with the two different surface topographies were either treated or left untreated. Treatment of the samples was carried out by immersing the surface into a $1 \%$ hetadecafluoro1,1,2,2-tetrahydro-decyl-1-trimethoxysilane $\left(\mathrm{CF}_{3}\left(\mathrm{CF}_{2}\right)_{7}\left(\mathrm{CH}_{2}\right)_{2} \mathrm{Si}\left(\mathrm{OCH}_{3}\right)_{3}\right.$ methanol solution for two hours. The surfaces were washed in $99 \%$ ethanol and dried in an oven at $80^{\circ} \mathrm{C}$ for 30 minutes $[15,30]$.

\subsection{Surface characterisation}

After the laser processing, the ablated debris and contaminants were removed from the surfaces by ultrasonically cleaning the samples with $99 \%$ ethanol for 10 minutes and drying them using 
compressed air. A Scanning Electron Microscope (SEM) (Philips XL30 FEG-SEM) incorporating Energy Dispersive X-ray Spectroscopy (EDX) was used for characterising the surface topography and the surface oxygen content respectively. Confocal Laser Microscopy (CLM) with an objective lens of $150 \mathrm{X}$ magnification was used to measure the surface roughness and an Atomic Force Microscopy (AFM) (Veeco Instruments Inc., UK) was used to investigate the nano-topographies of the surfaces and to determine the peak and valley widths and heights of the produced structures.

\subsubsection{Wettability measurements}

A sessile drop method using a contact angle analyser FTA 188 was used to examine the effects of the laser irradiation on the wettability characteristics of the samples. To measure the surface wettability, deionised water droplets $(6 \mu \mathrm{L})$ were deposited on the surfaces and the average of three measurements of the contact angles was recorded.

\subsubsection{Physicochemical measurements}

The contact angle of three liquids, water, $\alpha$-bromonaphthalene and formamide were measured to estimate the physicochemical parameters. After measuring the contact angle for the three liquids and using their surface tension components, the physicochemical parameters were obtained using a linear set of equations (Van Oss et al., 1989) [31].

$$
\begin{gathered}
(1+\cos \theta)_{\gamma_{L}}^{T O T}=2\left(\sqrt{\gamma_{S}^{L W} \gamma_{L}^{L W}}+\sqrt{\gamma_{S}^{+} \gamma_{L}^{-}}+\sqrt{\gamma_{S}^{-} \gamma_{L}^{-}}\right) \\
\Gamma^{\mathrm{TOT}}=\gamma^{\mathrm{LW}}+\gamma^{\mathrm{AB}} \ldots \ldots \ldots \ldots(2) \\
\gamma^{A B}=2 \sqrt{\gamma^{+} \gamma^{-}} \ldots \ldots \ldots \ldots \ldots .(3)
\end{gathered}
$$

where $\theta$ is the contact angle, $\gamma^{L W}$ is the Lifshitz-van der Waals component of the surface free energy, and $\gamma^{+}$and $\gamma^{-}$are the electron acceptor and donor parameters of the Lewis acid-base component $\gamma^{A B}$.

The surface hydrophobicity was calculated using: 
$\Delta G_{i w i}=-2\left(\sqrt{\gamma_{S}^{L W}}-\sqrt{\gamma_{L}^{L W}}\right)^{2}+4\left(\sqrt{\gamma_{S}^{+} \gamma_{W}^{-}}+\sqrt{\gamma_{S}^{-} \gamma_{W}^{-}}-\sqrt{\gamma_{S}^{+} \gamma_{S}^{-}}-\sqrt{\gamma_{W}^{+} \gamma_{W}^{-}}\right)$

\subsubsection{Bacterial retention}

A single colony of Escherichia coli (E. coli) bacteria (JM109 Promega UK) was incubated in $100 \mu \mathrm{L}$ of Lysogeny Broth (LB) (Sigma-Aldrich, UK) overnight at $37^{\circ} \mathrm{C}$ with orbital shaking at $225 \mathrm{rpm}$. The bacterial cells were washed in sterilised water three times by centrifuging (3500 rpm for 10 minutes), re-suspended in Lysogeny Broth (LB) and diluted to an optical density (OD) of 1.0 at $540 \mathrm{~nm}$.

Prior to the bacterial retention experiments, the laser textured and control (non-textured) surfaces were sterilised with $99 \%$ ethanol, washed with distilled water, placed in Petri dishes and incubated with bacterial solution at $37{ }^{\circ} \mathrm{C}$ for different periods (30 min and $24 \mathrm{hrs}$ ). Following incubation, the surfaces were carefully washed by dipping the samples in sterilised water. To fix the retained bacteria to the surfaces, the samples were incubated in a fume hood for 20 minutes at room temperature in $4 \%$ paraformaldehyde.

Prior to imaging, the DNA of the attached bacteria was stained using 4',6-diamidino-2phenylindole (DAPI) by adding $0.5 \mathrm{~mL}$ of $1 \mu \mathrm{g} / \mathrm{mL}$ DAPI onto the sample surfaces and incubated for 5 minutes and the samples washed using sterilised water utilising a bottle of a 3 $\mathrm{mm}$ nozzle diameter, at $45^{\circ}$ to the surface. The samples were fixed between two glass slides using CITYFLOUR and imaged using snapshot fluorescence microscopy. Nine images were taken for each surface, and the average number of $E$. coli was calculated using ImageJ.

The statistical analysis was performed using GraphPad Prism 8.2.1.441. Student's t test was used to determine the significant difference between the numbers of bacteria retention on surfaces. Statistical significance was settled at a probability value of $\mathrm{P}<0.05$. 


\section{Results and discussion}

\subsection{Surface morphology}

The picosecond laser is a powerful tool for producing micro/nano structures on various materials. An infrared laser was used to generate two self-organised periodic structures on the stainless steel substrate (Fig. 1). Scanning electron microscopy (Fig.1 a), an optical scanning microscopy (Fig.1 b), Atomic force microscopy (Fig.1 c) and a 2-D AFM profile (Fig. 1 d) were used to visualise the regular features generated at micro/nanoscale on the surfaces. The non-textured surface (the control) was noted to be flat using the SEM (Fig. 1a) with parallel lines of different width and depth and irregular spaces as seen using the OLM and AFM (Fig. $1 \mathrm{~b}, \mathrm{c})$. The control surface demonstrated the least maximum peaks' and valleys' width of 90 $\mathrm{nm}$ and height/depth of $2 \mathrm{~nm}$ (Fig. 2).

Two surfaces were produced on the stainless steel substrate using two different laserprocessing parameters. The surface generated using a low scanning speed $(100 \mathrm{~mm} / \mathrm{s})(\mathrm{S} 1)$ showed regularly spaced periodic structures (SEM and OLM, Fig. 1 a,b) with oval wavelets aligned in line patterns which had small rounded peaked structure (AFM, Fig. 1d). It had the largest maximum peaks width $(340 \mathrm{~nm})$ and height $(80 \mathrm{~nm})$ and the largest maximum valley width $(270 \mathrm{~nm})$ and height $(100 \mathrm{~nm})$ in comparison with other surfaces (Fig. 2). The surface produced using high scanning speed $(1000 \mathrm{~mm} / \mathrm{s})(\mathrm{S} 2)$ was observed to be a rough surface with irregular periodic structures (SEM and OLM, Fig. 1 a,d) and with spikes-like peaks of different dimensions (AFM, Fig. 1 d). It showed the least variation in surface features dimensions when compared to the control surface (OLM, Fig. $1 \mathrm{~b})$. It showed a maximum peak width $(80 \mathrm{~nm})$ and height $(10 \mathrm{~nm})$ and a maximum valley width $(110 \mathrm{~nm})$ and height $(10 \mathrm{~nm})$, which were slightly larger than that of the control surface and smaller than that of S1 (Fig. 2). As shown in Fig. 2, surface (S1) generated at low scanning speed $(100 \mathrm{~mm} / \mathrm{s})$ recorded higher periodicity of $587.4 \mathrm{~nm}$ than of $\mathrm{S} 2(95.8 \mathrm{~nm})$. 

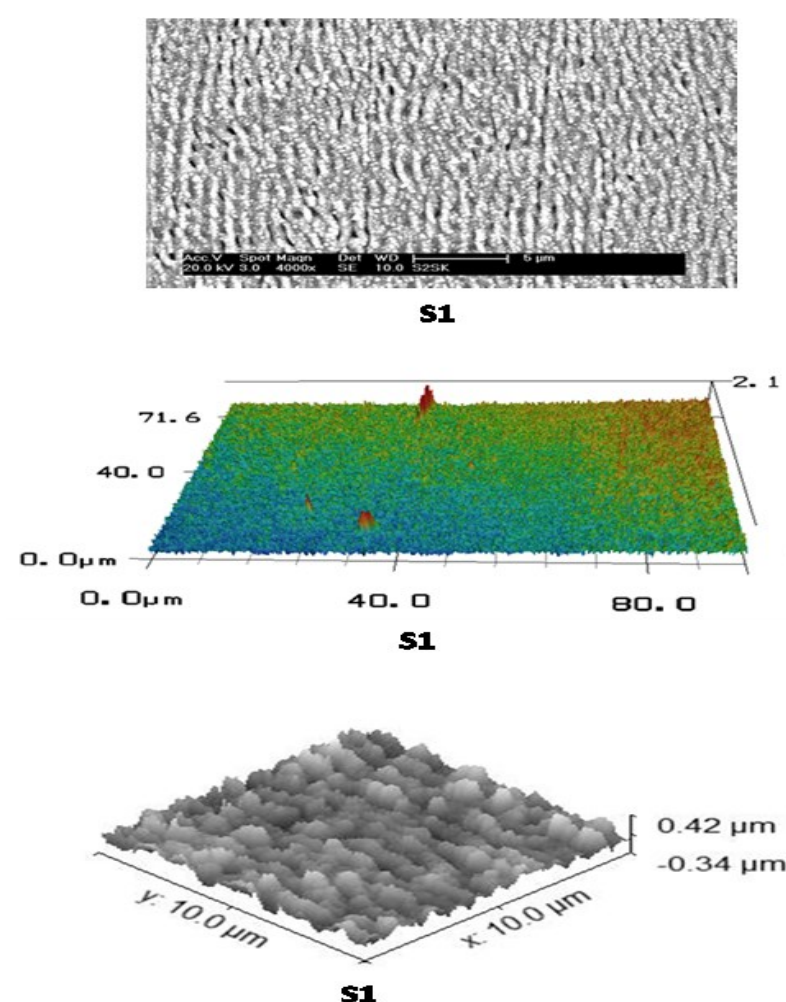

S1

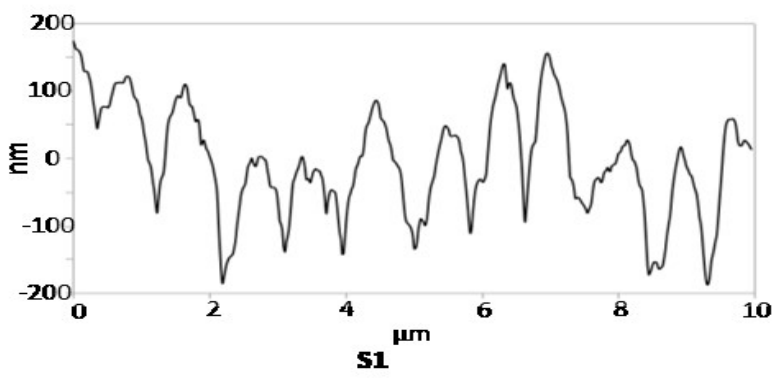

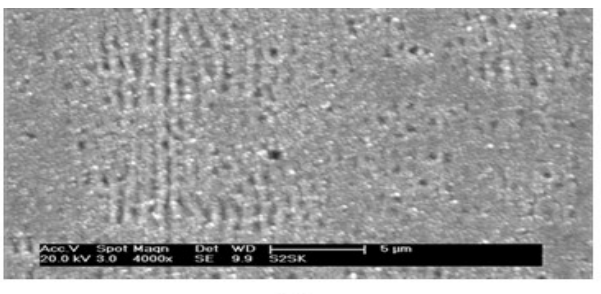

(e)

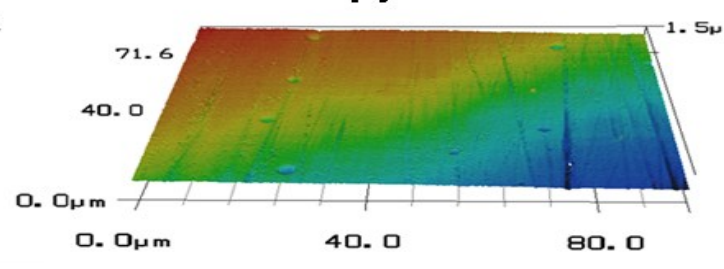

s2

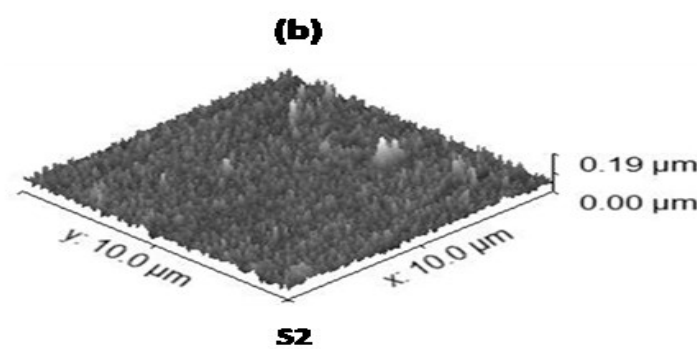

(c)

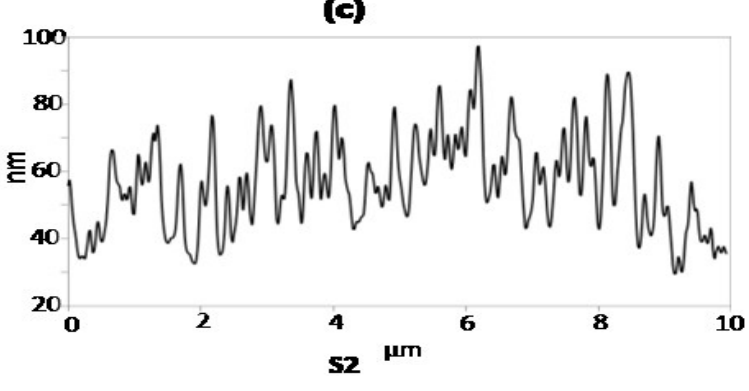

(d)

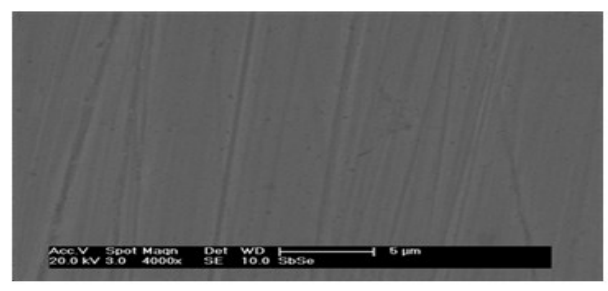

Control

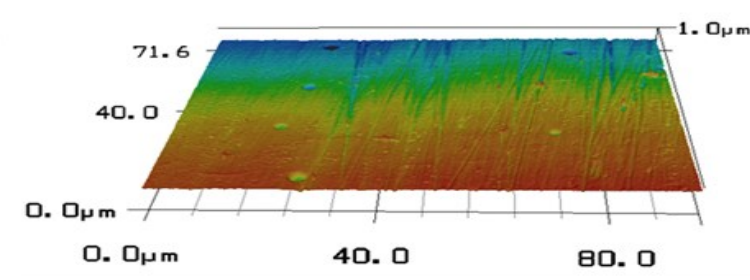

Control
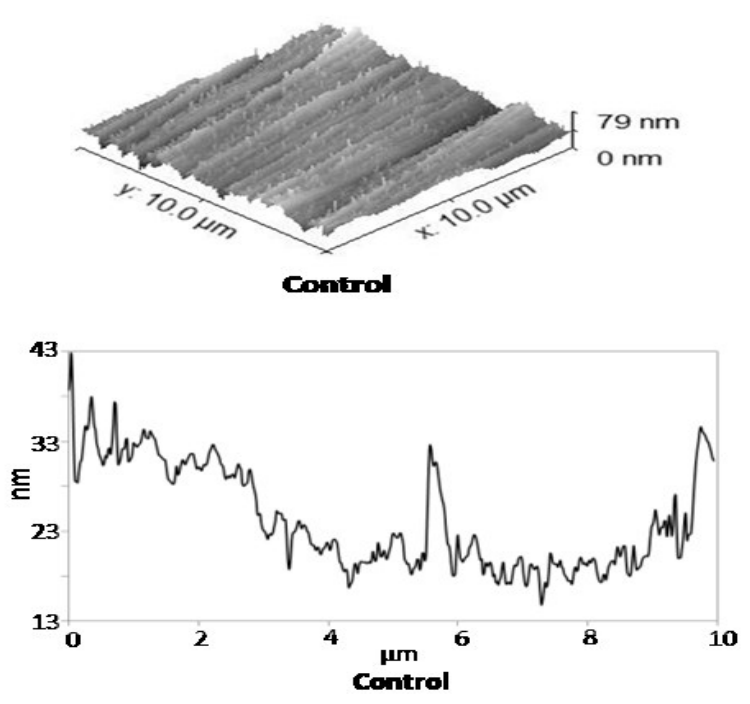

Fig. 1. (a) SEM images, (b) OLM images, (c) AFM images and (d) line profiler of laser treated surfaces and control surface. 


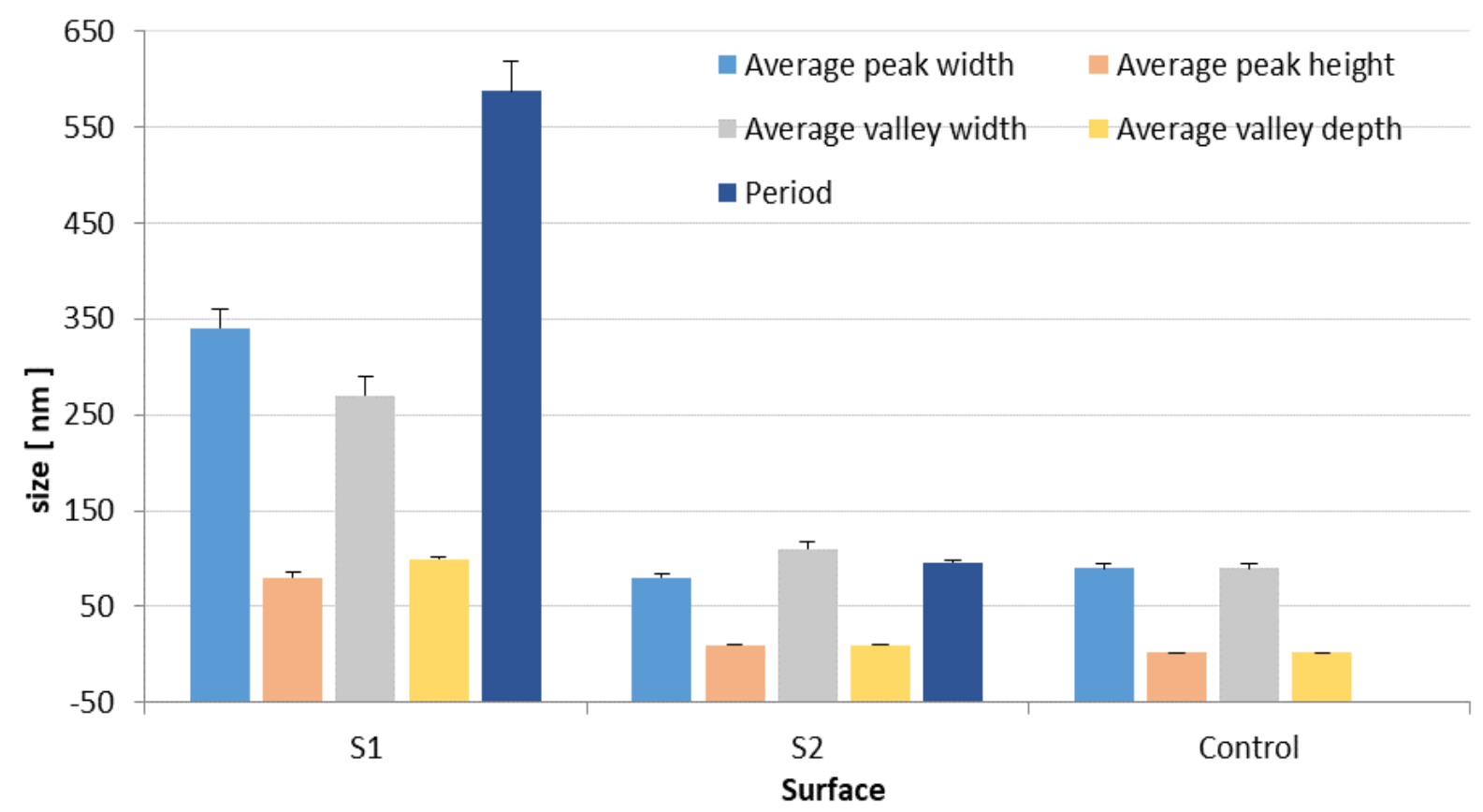

Fig. 2. Average maximum peaks and valleys width and height and the period of surfaces.

The average Roughness $\left(R_{a}\right)$, root mean square roughness $\left(R_{q}\right)$ and peak to valley ratio $\left(R_{p v}\right)$ are some of the surface topography measurements which have direct correlation to the surface topography and properties such as wettability, friction, adhesion, retention and attachment (Fig. 3). It was demonstrated that $\mathrm{S} 1$ recorded the highest $R_{a}, R_{q}$ and $R_{p v}$ values of $105.3 \mathrm{~nm}, 139.6$ $\mathrm{nm}, 1005.5 \mathrm{~nm}$ respectively. While sample S2 recorded slightly higher values of $19.2 \mathrm{~nm}, 27.3$ $\mathrm{nm}$ and $307.9 \mathrm{~nm}$ ) than that of control with only $11.5 \mathrm{~nm}, 16 \mathrm{~nm}$ and $94.4 \mathrm{~nm}$ respectively. The control surface demonstrated the smallest topographical values. 


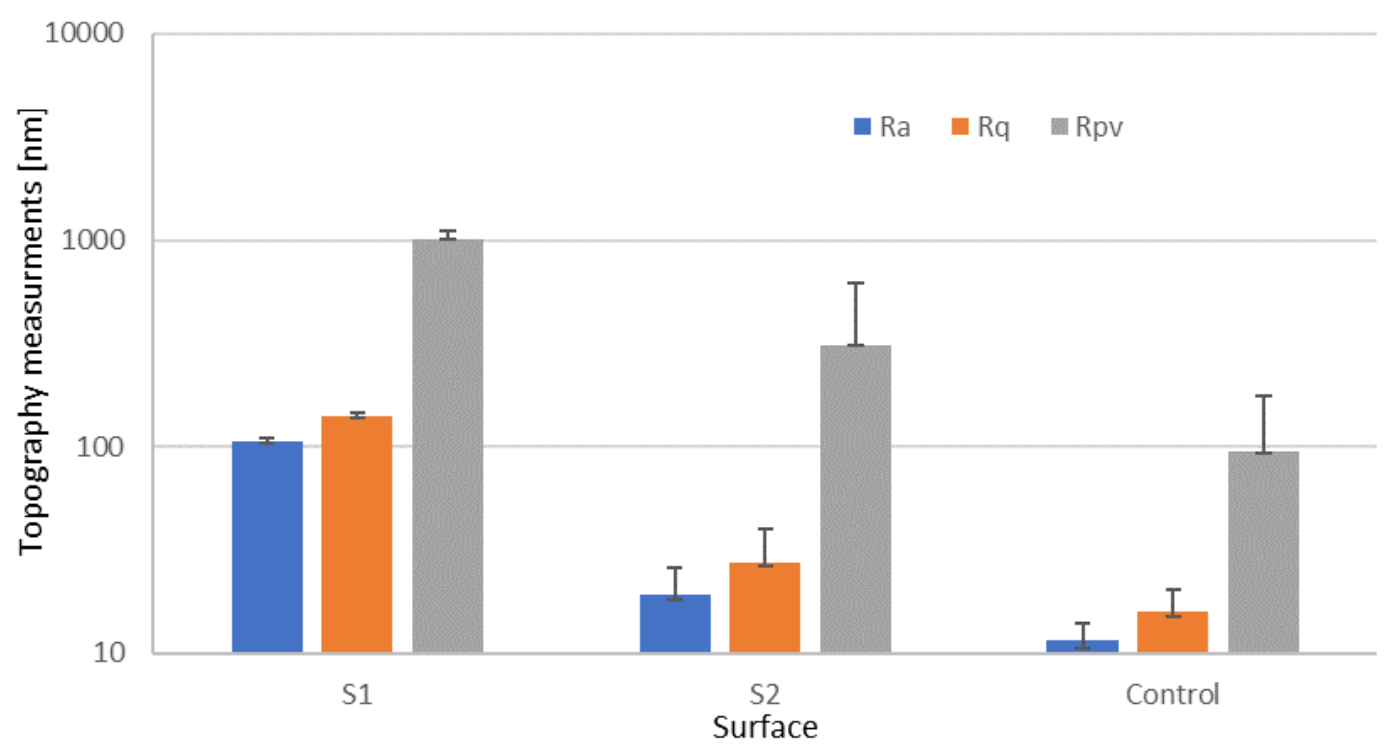

Fig. 3. Surface topography values for the laser treated stainless steel surfaces.

The overlapping in the direction of laser scanning $\left(L_{x}\right)$ was estimated as $[15,32]$ :

$$
L_{x}=\left(1-\frac{v_{x}}{f \times d}\right) \times 100 \%
$$

where $v_{x}$ is the scanning speed, $f$ is the pulse repetition rate, and $d$ is the focused spot size. The number of pulses/spot was calculated as [15,32]:

$$
N=\frac{f \times d}{v_{x}}
$$

These formula indicated that increasing the scanning speed at a specific pulse repetition rate and laser spot size resulted in decreasing the number of pulses and the overlapping. The two surfaces structure generated using picosecond laser were characterised as ripples or laser induced periodic surface structure (LIPSS) which significantly depended on the laser scanning parameters used. It was shown that increasing the scanning speed value by a factor of 10 led to a reduction in the number of pulses per spot from 129 pulses/spot in $\mathrm{S} 1$ to 13 pulses/spot in S2, which corresponded to an overlapping percentage of $99.9 \%(\mathrm{~S} 1)$ and $92 \%(\mathrm{~S} 2)$ in the direction of laser scanning. Changing the hatch distance, on the other hand, affected the 
overlapping in the direction perpendicular to the laser scanning which was calculated as $[15,32]:$

$$
L_{y}=\left(1-\frac{H}{d}\right) \times 100 \%
$$

where $H$ is the line to line distance, and $d$ is the focused spot size. The overlapping in the direction perpendicular to the laser scanning was $60 \%$ in S1 and $36 \%$ in S2. Therefore, it is clear that the change in the overlapping in both directions resulted in changes the surface's structures and roughness, which is mainly governed by the interaction time between the laser beam and the surface $[6,15,33]$. The longer interaction time caused by the large overlapping percentages and number of pulses results in inducing a more regular periodic structures and higher surface roughness (as seen in S1) compared to the irregular structure but smoother surface as shown in S2 [6,15,33].

\subsection{Characterisation of surface chemistry and wettability}

EDX data in Table 5 shows that the oxygen layer was increased with time as the oxygen percentage recorded after one month of laser treatment of laser treated surfaces (S1 and S2) was higher than that recorded one day of laser treatment. The oxygen percentage recorded by S1was higher (3.12\% (one day), $5.8 \%$ (one month), $3.2 \%$ (ACT)) in comparison with that recorded by S2 ((0.01\% (one day), $3.57 \%$ (one month), $0.00 \%$ (ACT)). The fluorine percentage of S1 was higher (1.43\%) than that of S2 $(0.87 \%)$ and control $(0.57 \%)$. The control surface recorded the least fluorine percentage. It has been reported that the oxygen layer that cover the surfaces after laser treatment is related to the oxygen molecules that exist in the air. As the laser treatment performed in air, the oxygen molecules react with the ablated particles during laser treatment and deposited on the surfaces $[15,34,35]$. In this work, with reducing the scanning speed, the interaction time between the laser and the surfaces was increased. Then, this resulted in increasing the reaction time between the oxygen molecules that exists in the 
surface environment and the surface. As S1 was treated using lower scanning speed $(100 \mathrm{~mm} / \mathrm{s})$ compared to S2 that treated using $1000 \mathrm{~mm} / \mathrm{s}$ scanning speed, S1 recorded the highest oxide layer compared to S2. It has also been reported that increasing the oxide layer on the surfaces affected to increase the carbon adsorption of the surfaces. The carbon adsorption of the surfaces increased the surface hydrophobicity. The oxide layer of metals increased with time affecting the carbon layer to increase [15,20-22]. Several mechanisms for the formation of the carbon layer over the laser treated surfaces were reported. As we focused on examine the laser treated surface after one day and one month of laser treatment, the EDX results showed that the carbon percentage increased with time. Indeed, it was reported by our previous work that the carbon layer was decreased by immersing the surfaces in water [24]. Therefore, the best explanation for the mechanism involved is that these carbon layer is related to the adsorption of the organic component from the atmosphere onto the laser produced oxide surface [36-38]. The adsorption of these organic components resulted in the formation of this carbon layer which interns affected the surface hydrophobicity to increase. This interprets the increase of hydrophobicity of the surfaces after one month. Indeed, as the fluorinated layer is mainly of fluorine carbon composition, S1 surface adsorb higher fluorine percentage compared to S2, which was related to the higher oxygen percentage of S1 compared to S2. As the oxygen percentage of the S1 surface was the highest recorded, there is likely to be high amount of SS-OH resulting in the higher level of fluorine percentage adsorption observed. Increasing the surface roughness and surface topographies measurements (average peaks and valleys width and height), on the other hand, means increasing the surface area. Therefore, a high roughness value of S1 might be another reason of increasing its oxygen and fluorine percentages [15,20-22]. 
Table 5. Atomic percentages of elements in the surfaces detected by EDX. Numbers between brackets are the standard deviation.

\begin{tabular}{|c|c|c|c|c|c|c|c|c|c|c|}
\hline \multirow{2}{*}{ Surface } & \multirow{2}{*}{ Time } & \multicolumn{9}{|c|}{ Element \% } \\
\hline & & $\mathbf{F e}$ & $\mathrm{Cr}$ & $\mathbf{N i}$ & Mo & $\mathbf{N}$ & $\mathbf{C}$ & $\mathrm{O}$ & $\mathrm{F}$ & $\mathrm{Si}$ \\
\hline \multirow{3}{*}{ S1 } & One Day & $62.745(0.27)$ & $16.82(0.83)$ & $9.425(0.91)$ & $1.92(0.06)$ & $4.155(0.16)$ & $1.84(0.35)$ & $3.12(0.28)$ & 0 & 0 \\
\hline & One Month & $58.795(2.12)$ & $16.485(0.37)$ & $8.275(0.45)$ & $1.915(0.05)$ & $6.225(0.99)$ & $2.545(0.04)$ & $5.765(1.87)$ & 0 & 0 \\
\hline & ACT* & $59.45(0.9)$ & $16.00(0.35)$ & $8.39(0.28)$ & $1.40(0.04)$ & $5.18(0.59)$ & $3.4(0.26)$ & $3.21(0.87)$ & $1.43(0.58)$ & $0.91(0.12)$ \\
\hline \multirow{3}{*}{ S2 } & One Day & $63.81(0.91)$ & $17(0.38)$ & $9.235(0.26)$ & $1.965(0.18)$ & $6.645(0.84)$ & $1.49(0.18)$ & $0.01(0.01)$ & 0 & 0 \\
\hline & One Month & $59.89(0.44)$ & $16.02(0.34)$ & $8.6(0.14)$ & $1.725(0.06)$ & $7.02(0.08)$ & $3.18(0.59)$ & $3.57(0.21)$ & 0 & 0 \\
\hline & $\mathrm{ACT}^{*}$ & $63.25(0.53)$ & $16.90(0.10)$ & $9.15(0.10)$ & $1.42(0.03)$ & $5.861 .83)$ & $2.93(0.7)$ & 0 & $0.87(0.03)$ & $0.6(0.02)$ \\
\hline \multicolumn{2}{|c|}{ Control } & $69.597(0.08)$ & $18.75(0.03)$ & $10.033(0.02)$ & $1.62(0.07)$ & 0 & 0 & 0 & 0 & 0 \\
\hline \multicolumn{2}{|c|}{ Control ACT* } & $64.86(0.08)$ & $17.28(0.10)$ & $9.38(0.14)$ & $1.41(0.13)$ & $3.96(0.07)$ & $1.91(0.00)$ & 0 & $0.57(0.08)$ & $0.61(0.21)$ \\
\hline
\end{tabular}

*ACT: Surface after chemical treatment. 
The contact angle (CA) was measured for the surfaces with and without chemical treatment (Fig.4). Without chemical treatment, the contact angle measurements were conducted after one day and after one month of the surfaces texturing. The chemical treatment was performed to reduce surface energy and to permanently stabilise the surface chemistry. Without chemical treatment and after one day, the results showed that both surfaces S1 and S2 were hydrophilic with CA values of $60.5^{\circ}$ and $76.3^{\circ}$ respectively. However, after one month of laser treatment both surfaces became hydrophobic with CA of $94^{\circ}$ and $100^{\circ}$ for S1 and S2 respectively. Both surfaces (S1 and S2) showed hydrophobic characteristics after chemical treatment following the laser treatment, and the CA of S1 $\left(132^{\circ}\right)$ was higher than that of S2 $\left(109^{\circ}\right)$ (Fig. 4). The non-textured surface (control) was hydrophobic after chemical treatment with CA of $\left(100^{\circ}\right)$ and without chemical treatment with $\mathrm{CA}$ of $\left(94^{\circ}\right)$. Without chemical treatment, S1 recorded the minimal CA, while it recorded the highest CA after chemical treatment. The contact angle after chemical treatment was measured directly after chemical treatment and it was constant with time.

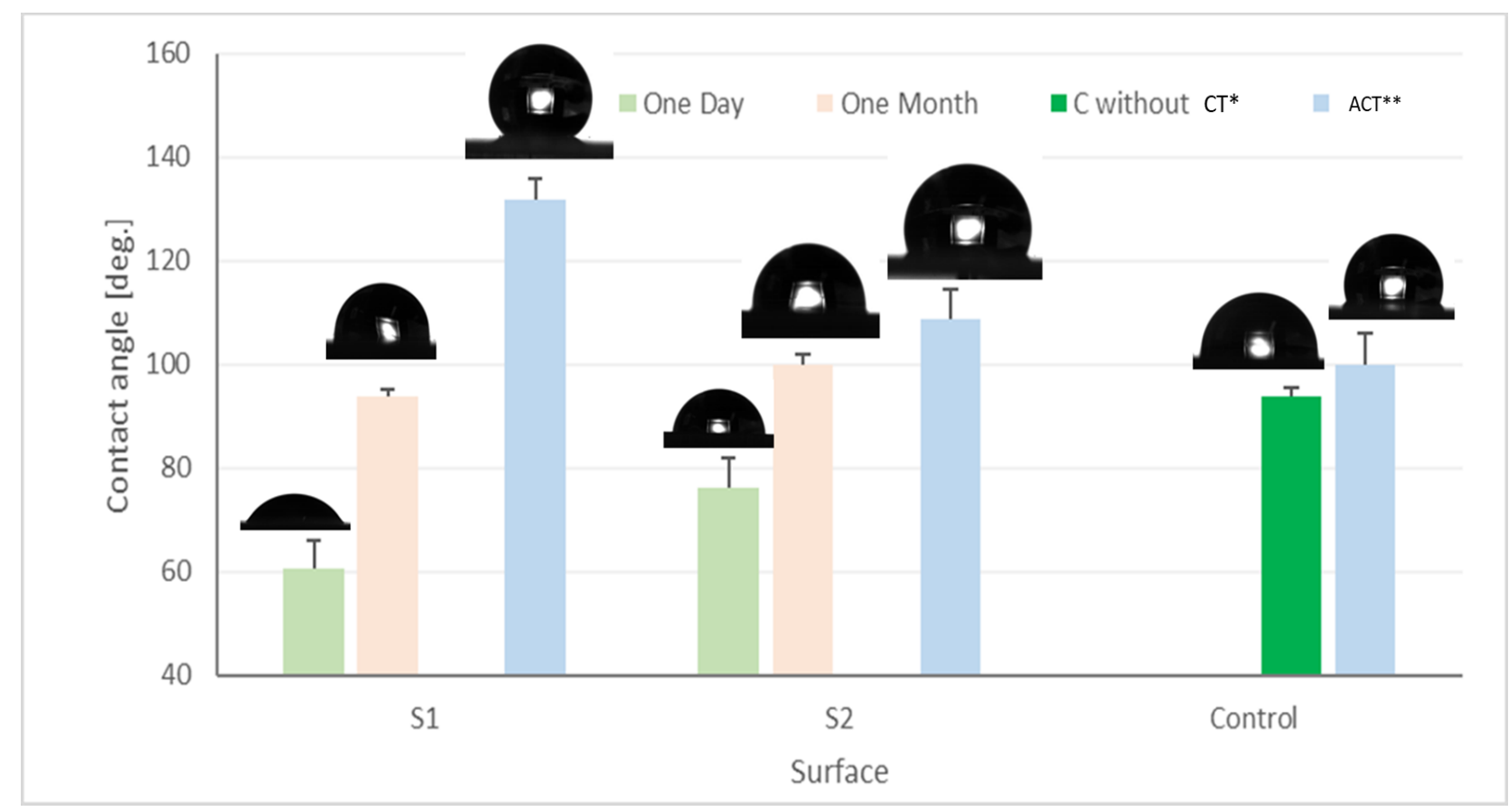

Fig. 4. Contact angle measurements of laser treated surfaces and the control surface. ${ }^{*} \mathrm{CT}$ refers to the control surface without chemical treatment. **ACT refers to the surfaces after chemical treatment. 
The free energy data of laser textured surfaces with and without chemical treatment is listed in Table 6. Without chemical treatment, it is clear that the surfaces' hydrophobicity increased while the surfaces' free energy was decreased with time. The hydrophobicity $\left(\Delta \mathbf{G}_{\mathbf{i w i}}\right)$ of both surfaces after one month of laser treatment $(\mathrm{S} 1=-66.54$ and $\mathrm{S} 2=-61.18)$ was higher than that recorded after one day of laser treatment $(\mathrm{S} 1=-25.85$ and $\mathrm{S} 2=-44.33)$. However, both surfaces recorded lower surface free energy components after one month of laser treatment compared to that recorded a day of laser treatment. The laser treated surface (S2) presented a minimal surface tension values $\left(\gamma_{\mathrm{s}}, \gamma_{\mathrm{s}}^{\mathrm{LW}}\right.$, and $\left.\gamma_{\mathrm{s}}^{-}\right)$compared to S1 and control surfaces. The surface S1 recorded surface tension values $\left(\gamma_{\mathrm{s}}=48.76, \gamma_{\mathrm{s}}{ }^{\mathrm{LW}}=41.49\right.$, and $\left.\gamma_{\mathrm{s}}{ }^{-}=14.89\right)$ after one day of laser treatment, and these values decreased to $\left(\gamma_{\mathrm{s}}=28.32, \gamma_{\mathrm{s}}{ }^{\mathrm{LW}}=27.15\right.$, and $\left.\gamma_{\mathrm{s}}{ }^{-}=2.29\right)$ after one month of laser treatment. However, the surface S2 recorded surface free energy values $\left(\gamma_{\mathrm{s}}=\right.$ $39.38, \gamma_{\mathrm{s}}{ }^{\mathrm{LW}}=37.12$, and $\left.\gamma_{\mathrm{s}}{ }^{-}=8.34\right)$ after one day of laser treatment which they declined to $\left(\gamma_{\mathrm{s}}\right.$ $=26.29, \gamma_{\mathrm{s}}{ }^{\mathrm{LW}}=24.84$, and $\left.\gamma_{\mathrm{s}}{ }^{-}=3.10\right)$ after one month of laser treatment. The control surface presented the highest surface tension values $\left(\gamma_{\mathrm{s}}=42.06, \gamma_{\mathrm{s}}{ }^{\mathrm{LW}}=38.62\right.$, and $\left.\gamma_{\mathrm{s}}{ }^{-}=2.81\right)$ compared to that recorded by S1 and S2 after one month of laser treatment. After chemical treatment, all surfaces presented higher hydrophobicity and lower surface tension values $\left(\gamma_{\mathrm{s}}, \gamma_{\mathrm{s}}^{\mathrm{LW}}\right.$, and $\left.\gamma_{\mathrm{s}}{ }^{-}\right)$ compared to the values obtained without chemical treatment. The laser treated surface (S1) recorded surface tension values $\left(\gamma_{\mathrm{s}}=13.81, \gamma_{\mathrm{s}}{ }^{\mathrm{LW}}=13.37\right.$, and $\left.\gamma_{\mathrm{s}}{ }^{-}=0.13\right)$ which were lower than that obtained from S2 $\left(\gamma_{\mathrm{s}}=18.92, \gamma_{\mathrm{s}}{ }^{\mathrm{LW}}=18.69\right.$, and $\left.\gamma_{\mathrm{s}}{ }^{-}=0.59\right)$ and control $\left(\gamma_{\mathrm{s}}=32.21, \gamma_{\mathrm{s}}{ }^{\mathrm{LW}}=\right.$ 32.02, and $\gamma_{\mathrm{s}}{ }^{-}=0.27$ ) surfaces. Furthermore, the control surface presented the highest hydrophobicity and surface energy values after chemical treatment. 
Table 6. Free energy $\left(\mathrm{mJ} / \mathrm{m}^{2}\right)$ results of surfaces.

\begin{tabular}{|c|c|c|c|c|c|c|c|}
\hline Surface & Time & $\Delta \mathbf{G}_{\text {iwi }}$ & Ys & $Y s^{L W}$ & $Y_{s}^{A B}$ & $\mathrm{Ys}^{+}$ & $Y_{s^{-}}$ \\
\hline \multirow{3}{*}{ S1 } & One day & -25.85 & 48.76 & 41.49 & 7.27 & 0.89 & 14.89 \\
\hline & One month & -66.54 & 28.32 & 27.15 & 1.17 & 0.15 & 2.29 \\
\hline & $\mathrm{ACT}^{*}$ & -85.26 & 13.81 & 13.37 & 0.44 & 0.38 & 0.13 \\
\hline \multirow{3}{*}{ S2 } & One day & -44.33 & 39.38 & 37.13 & 2.26 & 0.15 & 8.35 \\
\hline & One month & -61.18 & 26.3 & 24.84 & 1.46 & 0.17 & 3.1 \\
\hline & $\mathrm{ACT}^{*}$ & -84.22 & 18.92 & 18.69 & 0.23 & 0.02 & 0.59 \\
\hline \multicolumn{2}{|c|}{ Control } & -59.07 & 42.06 & 38.62 & 3.44 & 1.06 & 2.81 \\
\hline \multicolumn{2}{|c|}{ Control ACT* } & -90.1191 & 32.212 & 32.02 & 0.19 & 0.04 & 0.27 \\
\hline
\end{tabular}

*ACT: Surface after chemical treatment.

In this study, chemically treated and non-chemically treated surfaces were compared. The nonchemically treated laser surfaces demonstrated an increased surface roughness and decreased the contact angle. This effect may be due to the water droplet filling the areas between the surface features which resulted in increasing the surface wettability and thus the surfaces becoming hydrophilic. Without chemical treatment, the surface with the higher surface roughness (S1) recorded the highest wettability. The higher wettability of the rougher surface (S1), when compared to the surface with the lowered roughness (S2), can be explained by the Wenzel model, which explains the effect of surface roughness on surface wettability. The Wenzel model demonstrates the linear relationship between surface roughness and wettability. 
As a result of increasing the roughness, the CA decreased resulting in an increase in the wettability $[39,40]$.

After one month of laser treatment, the surface wetability was decreased and the laser treated surfaces demonstrated hydrophobic properties. This change in surface hydrophobicity may be related to the adsorption of the organic components from the atmosphere which present as a carbon layer during the EDX analysis of the surfaces [36,41]. Since the oxygen and carbon percentages increased this might be an indication of $\mathrm{CO}_{2}$ formation [38]. The change in wettability may also have decreased due to the changes in the surface chemistry resulting in air becoming trapped between surface features. This may be explained by Cassie-Baxter state where the contact angle was increased by means of increasing the trapped air between features with increasing the surface roughness [42].

\subsection{Microbiology}

The retention of bacteria was determined using retention microbiology assay. The snapshot fluorescence microscopy images of $E$. coli bacteria attached on all surfaces following the microbiology assay were demonstrated (Fig. 5). The average number of attached bacteria was investigated (Fig. 6). It is clear that the number of bacteria retained on all surfaces was increased by increasing the incubation time from 30 minutes to 24 hours. Without reducing the surface tension, and after one day of laser treatment, the results showed that the bacteria retention was increased with increasing the surface roughness and wettability as S1 recorded the highest number of bacteria retention $\left(9.733 \times 10^{3}\right)$ compared to that attached to S2 $\left(6.028 \times 10^{3}\right)$ and to the control $\left(5.773 \times 10^{3}\right)$. Furthermore, after one month of laser treatment, surfaces' wettability behaviour and the number of bacteria retained on both surfaces S1 and S2 was reduced. The surface of the least roughness and CA (S2) recorded a slightly higher number of retention bacteria $\left(6.012 \times 10^{3}\right)$ in comparison to $\mathrm{S} 1\left(5.998 \times 10^{3}\right)$. Without chemical 
treatment, the control surface recorded the lowest number of bacterial retention. With reducing the surface tension after chemical treatment, the results showed a further decrease in the number of bacterial retention on all surfaces. S1 presented the lowest number of retained bacteria $\left(3.065 \times 10^{3}\right)$ compared to S2 $\left(4.365 \times 10^{3}\right)$ and control $\left(4.894 \times 10^{3}\right)$. Furthermore, the control surface recorded the highest number of retention bacteria. Thus, it can be said that reducing the surface tension after chemical treatment played an important role in reducing the bacterial retention on the surfaces. Overall, it can be said that the surface hydrophobicity and reducing the surface tension are both important for reducing the bacteria retention. Statistically, without chemical treatment, after 30 minutes of incubation, the results showed a significant difference $(\mathrm{P}<0.05)$ between all surfaces in the mean $\pm \mathrm{SE}$ values of the number of bacterial retained. However, after one month of laser treatment and $24 \mathrm{hrs}$ incubation, no significant $(\mathrm{P}>$ $0.05)$ differences between all surfaces were observed in the mean \pm SE values of the number of retained bacteria. Furthermore, with reducing the surface energy, after chemical treatment, a significant difference $(\mathrm{P}<0.05)$ between $\mathrm{S} 1$ and $\mathrm{S} 2$, and between $\mathrm{S} 1$ and control in the mean $\pm \mathrm{SE}$ values of the number of bacteria retained.

An understanding of how surface properties affect bacteria retention may help in manufacturing the surfaces to depress the bacteria fouling. It was reported that several factors such as surface chemistry, topography, energy, and wettability affect the retention of bacteria on the surfaces. While some research stated that bacteria adhesion was improved by increasing the surface roughness due to the increased contact area between bacteria and the surface [43], others claimed no relationship between bacteria adhesion and surface roughness [44]. The latter research demonstrated that increasing the surface roughness can lead to trapping air within the surface trenches, decreasing the surface wettability and significantly reducing the contact area [45]. Rebollar et al. [46], related the increase of cell adhesion on laser induced periodic structures on polymer substrates due to the increase in the surface free energy. 
Without chemical treatment, our results showed that surfaces of higher roughness recorded the largest bacteria retention, while showing the lowest bacterial retention after chemical treatment. Furthermore, our results showed that chemically treated surfaces of large contact angle and low free surface energy recorded minimal bacterial retention. After chemical treatment, the surface free energy decreased and the laser treated surfaces (such as S1) showed lower surface tension than the control surface, decreasing bacteria retention.

Without chemical treatment, the surface hydrophobicity increased with time and the laser treated surfaces recorded higher hydrophobicity after one month compared to control surface. However, the hydrophobicity of all surfaces significantly increased after chemical treatment, with the control surface recording the highest value although it retained the largest number of bacteria colonies.

The surface free energy of laser treated surface decreased with time and the laser treated surfaces recorded lowest energy components values compared to control surface. Furthermore, after one month of laser treatment, within the first 30 minutes of incubation, the number of bacteria retained on laser treated surfaces was low compared to the control surface. However, after 24 hours of incubation, the behaviour was reverted, and the control surface recorded the lowest number of bacteria colonies instead. This trend may be related to the instability of the surface hydrophobicity that could be lost over time during incubation of laser treated surfaces when immersed in water.

Work Rajab et al. [24], which focused on studying the effect of processing time on the surface wettability of laser treated stainless steel surfaces, demonstrated that chemical treatment stabilises surface hydrophobicity and helps laser treated surfaces to maintain hydrophobicity for longer time than control surface. This might be the reason behind the reduced bacterial retention on laser treated surface after chemical treatment. 
After chemical treatment, the surface tension was decreased and the contact area between bacteria and surface was decreased due to the presence of the air pockets between surface features, resulting in reduced bacteria retention.

The results of this work proved that stabilising the surface wettability, by reducing surface energy with chemical treatment after laser treatment, is an important factor for reducing the bacteria retention. It was also demonstrated that only generating hydrophobic surfaces was not adequate to reduce the bacteria retention and this should be accompanied with reducing the surface energy and stabilising the surface wettability. 


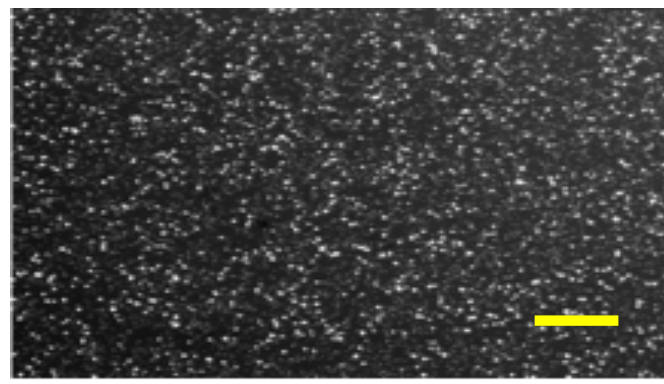

One day

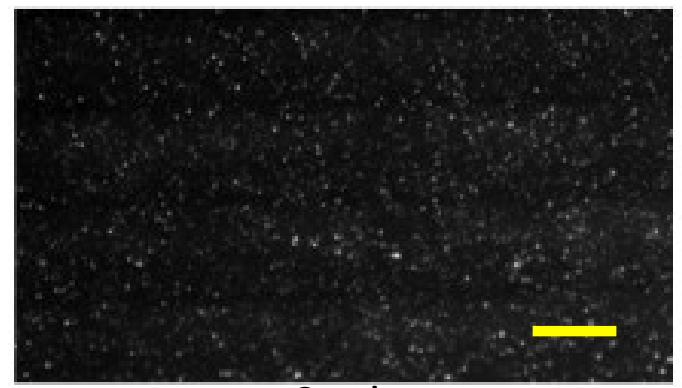

One day

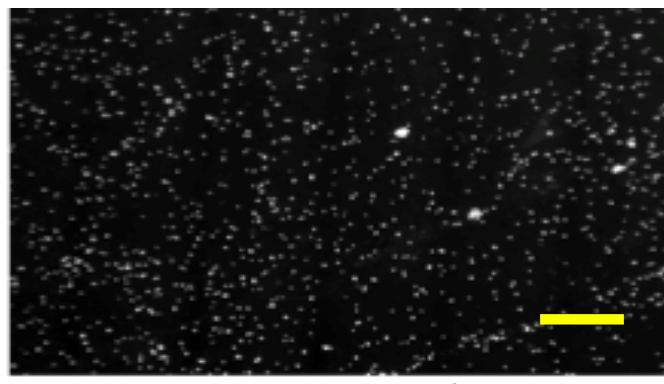

One month

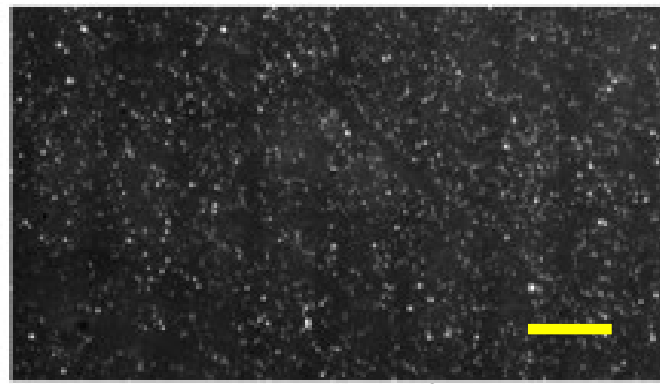

One month

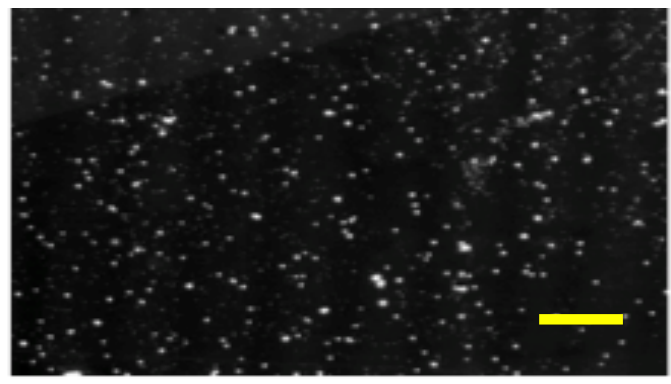

ACT

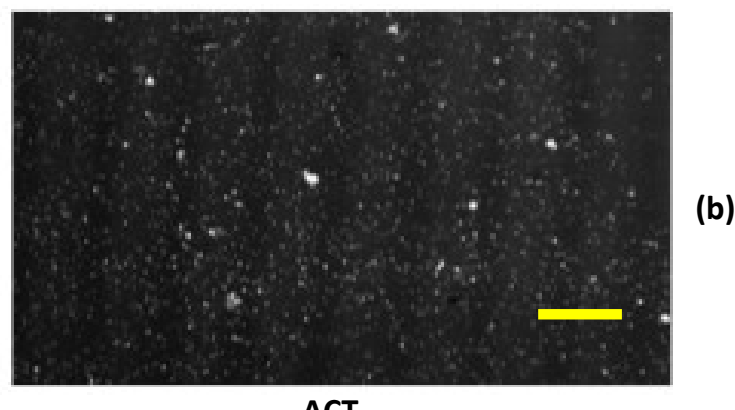

ACT

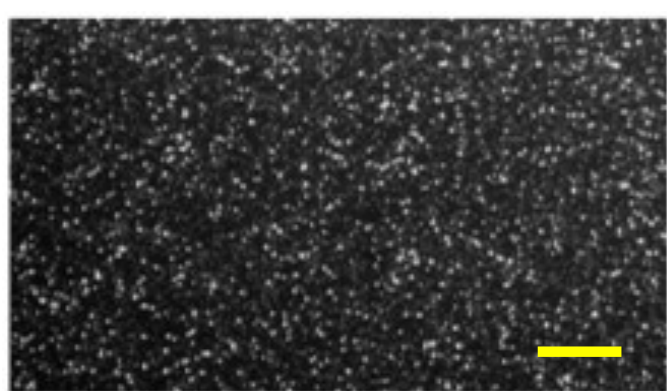

Control

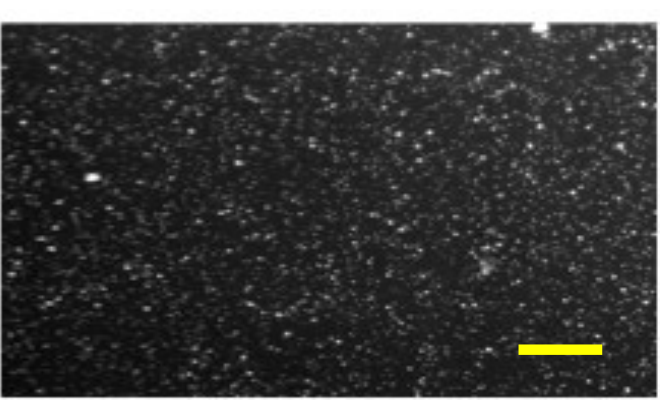

Control ACT (a)

(b)

Fig. 5. Snapshot florescence microscopy images of the distribution of the bacteria across the surfaces following the microbiological assay using 10X magnification lens, (a) S1 surface, (b) S2 surface and (c) control with and without chemical treatment. Scale bar $=100 \mu \mathrm{m}$. 


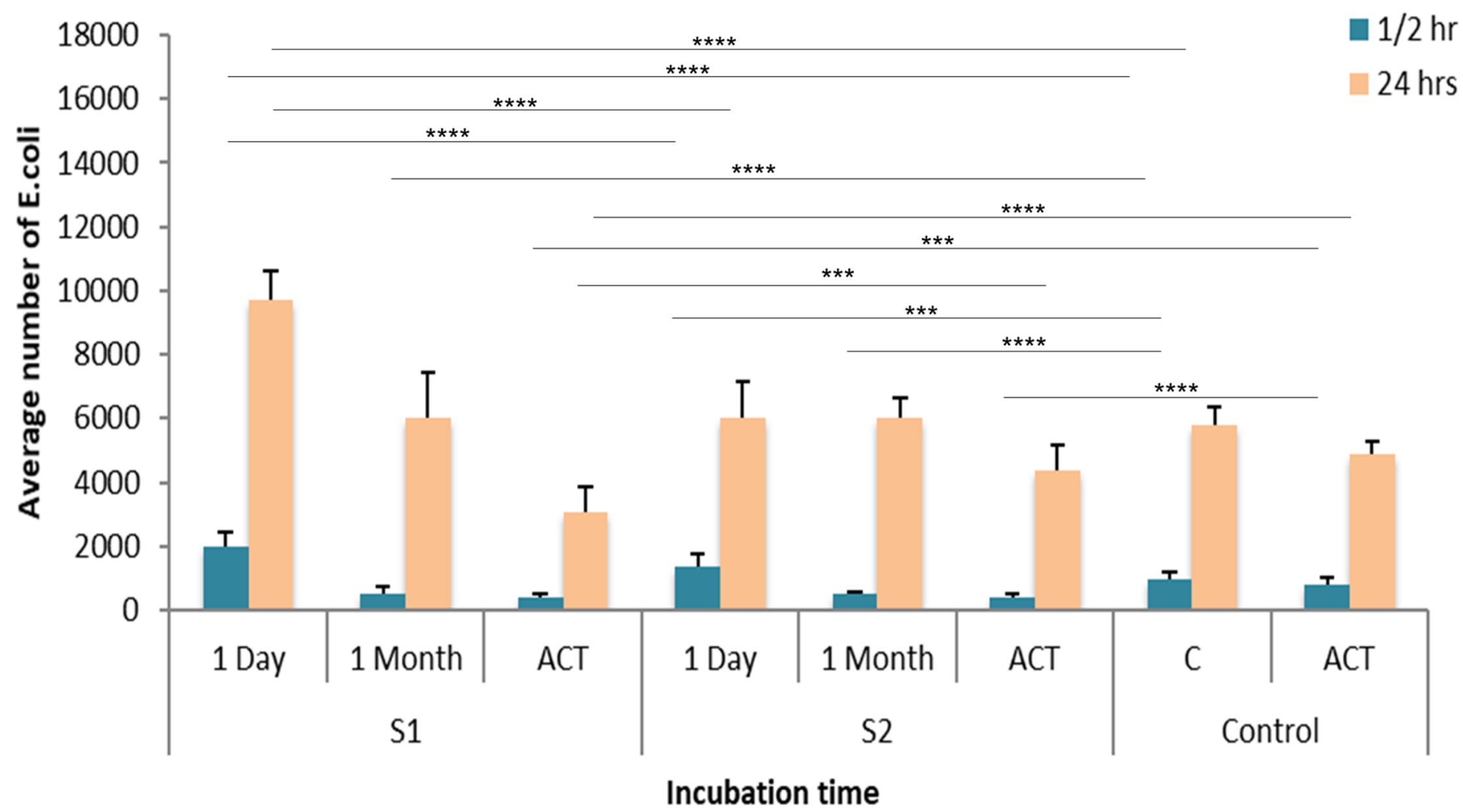

Fig. 6. Average number of E. coli retained on laser textured stainless steel surfaces and control surface following the microbiological assay. ACT: surfaces after chemical treatment. 


\section{Conclusions}

In this work, the bacterial properties of two surfaces induced using picosecond laser on stainless steel substrate were investigated. It was demonstrated that the surface wettability, roughness and energy affected the average number of bacteria retained. Without chemical treatment, the results proved that the surface with the highest surface roughness, lowest contact angle and highest surface free energy value resulted in the highest number of bacteria retained. The results also showed that the surface chemistry was changed with time as the surface free energy of laser treated surfaces was decreased resulting in decreased bacterial retention. With chemical treatment, the surface of the highest roughness and contact angle and lowest free energy components presented the lowest number of bacteria retained as a result of reducing the contact area between the bacteria and the surface. The results demonstrated that stabilising the surface wettability and reducing surface energy are important factors, which in tandem with the surface roughness reduced bacterial retention.

\section{Acknowledgment}

The authors acknowledge The University of Manchester especially Professor Lin Li for facilitating doing this work in their laboratories. 


\section{References}

[1] M. Birnbaum, Semiconductor surface damage produced by ruby lasers, J. Appl. Phys. 36 (1965) 3688-3689.

[2] J.V. Obona, V. Ocelík, J.Z.P. Skolski, V.S. Mitko, G. Römer, A.J. Huis, J.T.M. De Hosson, On the surface topography of ultrashort laser pulse treated steel surfaces, Appl. Surf. Sci. 258 (2011) 1555-1560.

[3] S. Bashir, M.S. Rafique, A. Ajami, W. Husinsky, The growth of nanoscale periodic and dot-like structures on the surface of stainless steel with femtosecond laser pulses in the dry and wet ambient environment, Appl. Phys. A. 113 (2013) 673-681.

[4] A.Y. Vorobyev, C. Guo, Femtosecond laser nanostructuring of metals, Opt. Express. 14 (2006) 2164-2169.

[5] T.T. Dai Huynh, A. Petit, N. Semmar, Picosecond laser induced periodic surface structure on copper thin films, Appl. Surf. Sci. 302 (2014) 109-113.

[6] K.M.T. Ahmmed, E.J.Y. Ling, P. Servio, A.-M. Kietzig, Introducing a new optimization tool for femtosecond laser-induced surface texturing on titanium, stainless steel, aluminum and copper, Opt. Lasers Eng. 66 (2015) 258-268.

[7] Q.Z. Zhao, S. Malzer, L.J. Wang, Formation of subwavelength periodic structures on tungsten induced by ultrashort laser pulses, Opt. Lett. 32 (2007) 1932-1934.

[8] K. Okamuro, M. Hashida, Y. Miyasaka, Y. Ikuta, S. Tokita, S. Sakabe, Laser fluence dependence of periodic grating structures formed on metal surfaces under femtosecond laser pulse irradiation, Phys. Rev. B. 82 (2010) 165417.

[9] J. Long, P. Fan, M. Zhong, H. Zhang, Y. Xie, C. Lin, Superhydrophobic and colorful copper surfaces fabricated by picosecond laser induced periodic nanostructures, Appl. Surf. Sci. 311 (2014) 461-467.

[10] A.Y. Vorobyev, C. Guo, Femtosecond laser-induced periodic surface structure formation on tungsten, J. Appl. Phys. 104 (2008) 63523.

[11] Y.C. Guan, W. Zhou, Z.L. Li, H.Y. Zheng, Femtosecond laser-induced iridescent effect on AZ31B magnesium alloy surface, J. Phys. D. Appl. Phys. 46 (2013) 425305.

[12] B. Liu, W. Wang, G. Jiang, X. Mei, K. Wang, J. Wang, Formation of porous structure with subspot size under the irradiation of picosecond laser pulses, J. Nanomater. 2013 (2013).

[13] B. Liu, G. Jiang, W. Wang, X. Mei, K. Wang, J. Cui, J. Wang, Porous microstructures induced by picosecond laser scanning irradiation on stainless steel surface, Opt. Lasers Eng. 78 (2016) 55-63.

[14] M. Groenendijk, J. Meijer, Microstructuring using femtosecond pulsed laser ablation, in: Int. Congr. Appl. Lasers Electro-Optics, Laser Institute of America, 2005: p. M408.

[15] F.H. Rajab, D. Whitehead, Z. Liu, L. Li, Characteristics of hierarchical micro/nano surface structure formation generated by picosecond laser processing in water and air, Appl. Phys. B Lasers Opt. 123 (2017). https://doi.org/10.1007/s00340-017-6858-9.

[16] C. Albu, A. Dinescu, M. Filipescu, M. Ulmeanu, M. Zamfirescu, Periodical structures induced by femtosecond laser on metals in air and liquid environments, Appl. Surf. 
Sci. 278 (2013) 347-351.

[17] B.K. Nayak, M.C. Gupta, Ultrafast laser-induced self-organized conical micro/nano surface structures and their origin, Opt. Lasers Eng. 48 (2010) 966-973.

[18] Y.Y. Yan, N. Gao, W. Barthlott, Mimicking natural superhydrophobic surfaces and grasping the wetting process: A review on recent progress in preparing superhydrophobic surfaces, Adv. Colloid Interface Sci. 169 (2011) 80-105.

[19] E. Fadeeva, V.K. Truong, M. Stiesch, B.N. Chichkov, R.J. Crawford, J. Wang, E.P. Ivanova, Bacterial retention on superhydrophobic titanium surfaces fabricated by femtosecond laser ablation, Langmuir. 27 (2011) 3012-3019.

[20] F. Rajab, P.S. Benson, L. Li, K.A. Whitehead, Picosecond Laser Surface Micro/Nano Texturing of Stainless Steel as a Method to Reduce the Adhesion of Bacteria., in: Proc. LPM2017-the 18th Int. Symp. Laser Precis. Microfabr., 2017.

[21] F.H. Rajab, C.M. Liauw, P.S. Benson, L. Li, K.A. Whitehead, Production of hybrid macro/micro/nano surface structures on Ti6Al4V surfaces by picosecond laser surface texturing and their antifouling characteristics, Colloids Surfaces B Biointerfaces. 160 (2017). https://doi.org/10.1016/j.colsurfb.2017.10.008.

[22] F.H. Rajab, C.M. Liauw, P.S. Benson, L. Li, K.A. Whitehead, Picosecond laser treatment production of hierarchical structured stainless steel to reduce bacterial fouling, Food Bioprod. Process. 109 (2018). https://doi.org/10.1016/j.fbp.2018.02.009.

[23] J. Yong, F. Chen, Q. Yang, X. Hou, Femtosecond laser controlled wettability of solid surfaces, Soft Matter. 11 (2015) 8897-8906.

[24] F.H. Rajab, Z. Liu, L. Li, Long term superhydrophobic and hybrid superhydrophobic/superhydrophilic surfaces produced by laser surface micro/nano surface structuring, Appl. Surf. Sci. 466 (2019) 808-821. https://doi.org/10.1016/j.apsusc.2018.10.099.

[25] K.C. Mills, Recommended values of thermophysical properties for selected commercial alloys, Woodhead Publishing, 2002.

[26] E.A. Brandes, G.B. Brook, Smithells metals reference book, Elsevier, 2013.

[27] T. Dobrev, D.T. Pham, S.S. Dimov, A simulation model for crater formation in laser milling, W. Menz SS Dimov M. 4 (2005) 2005.

[28] Gophotonics.com, PX-Series-EdgeWave | Laser, in, 2018., n.d.

[29] O.B. Otanocha, L. Li, S. Zhong, Z. Liu, High Power Picosecond Laser Surface Microtexturing of H13 Tool Steel and Pattern Replication onto ABS Plastics via Injection Moulding, Lasers Manuf. Mater. Process. 3 (2016) 22-49.

[30] J. Long, P. Fan, D. Gong, D. Jiang, H. Zhang, L. Li, M. Zhong, Superhydrophobic surfaces fabricated by femtosecond laser with tunable water adhesion: from lotus leaf to rose petal, ACS Appl. Mater. Interfaces. 7 (2015) 9858-9865.

[31] C.J. Van Oss, L. Ju, M.K. Chaudhury, R.J. Good, Estimation of the polar parameters of the surface tension of liquids by contact angle measurements on gels, J. Colloid Interface Sci. 128 (1989) 313-319.

[32] J. Lehr, A.-M. Kietzig, Production of homogenous micro-structures by femtosecond 
laser micro-machining, Opt. Lasers Eng. 57 (2014) 121-129.

[33] Y. Li, Z. Cui, W. Wang, C. Lin, H.-L. Tsai, Formation of linked nanostructuretextured mound-shaped microstructures on stainless steel surface via femtosecond laser ablation, Appl. Surf. Sci. 324 (2015) 775-783.

[34] S. Razi, K. Madanipour, M. Mollabashi, Laser surface texturing of 316L stainless steel in air and water: A method for increasing hydrophilicity via direct creation of microstructures, Opt. Laser Technol. 80 (2016) 237-246.

[35] C.Y. Cui, X.G. Cui, X.D. Ren, M.J. Qi, J.D. Hu, Y.M. Wang, Surface oxidation phenomenon and mechanism of AISI 304 stainless steel induced by Nd: YAG pulsed laser, Appl. Surf. Sci. 305 (2014) 817-824.

[36] J. Long, M. Zhong, H. Zhang, P. Fan, Superhydrophilicity to superhydrophobicity transition of picosecond laser microstructured aluminum in ambient air, J. Colloid Interface Sci. 441 (2015) 1-9.

[37] S. Takeda, M. Fukawa, Y. Hayashi, K. Matsumoto, Surface OH group governing adsorption properties of metal oxide films, Thin Solid Films. 339 (1999) 220-224.

[38] A.-M. Kietzig, S.G. Hatzikiriakos, P. Englezos, Patterned superhydrophobic metallic surfaces, Langmuir. 25 (2009) 4821-4827.

[39] R.N. Wenzel, Resistance of solid surfaces to wetting by water, Ind. Eng. Chem. 28 (1936) 988-994.

[40] R.N. Wenzel, Surface roughness and contact angle., J. Phys. Chem. 53 (1949) 14661467.

[41] N. Shchedrina, Y. Karlagina, T.E. Itina, A. Ramos, D. Correa, A. TokmachevaKolobova, S. Manokhin, D. Lutoshina, R. Yatsuk, I. Krylach, Wetting angle stability of steel surface structures after laser treatment, Opt. Quantum Electron. 52 (2020) 112.

[42] A.B.D. Cassie, Contact angles, Discuss. Faraday Soc. 3 (1948) 11-16.

[43] K.A. Whitehead, J. Colligon, J. Verran, Retention of microbial cells in substratum surface features of micrometer and sub-micrometer dimensions, Colloids Surfaces B Biointerfaces. 41 (2005) 129-138.

[44] S. Flint, N. Hartley, A modified selective medium for the detection of Pseudomonas species that cause spoilage of milk and dairy products, Int. Dairy J. 6 (1996) 223-230.

[45] J. Ma, Y. Sun, K. Gleichauf, J. Lou, Q. Li, Nanostructure on taro leaves resists fouling by colloids and bacteria under submerged conditions, Langmuir. 27 (2011) 1003510040.

[46] E. Rebollar, S. Pérez, M. Hernández, C. Domingo, M. Martín, T.A. Ezquerra, J.P. García-Ruiz, M. Castillejo, Physicochemical modifications accompanying UV laser induced surface structures on poly (ethylene terephthalate) and their effect on adhesion of mesenchymal cells, Phys. Chem. Chem. Phys. 16 (2014) 17551-17559. 